\title{
Topofilia e Topofobia em $O$ Sertanejo: Uma Análise Ecocrítica do Regionalismo Alencarino
}

\section{Topophilia and Topophobia in The Sertanejo: An Ecocritical Analysis of the Alencarian Regionalism}

\author{
Elisângela Campos Damasceno Sarmento \\ Doutoranda em Ecologia Humana e Gestão Socioambiental, IFPI \\ elisceno@ifpi.edu.br \\ Geraldo Jorge Barbosa de Moura \\ Pós-Doutor em Comportamento, UFRPE \\ geraldo.jbmoura@ufrpe.br
}

\begin{abstract}
Resumo
Esta pesquisa propõe investigar, sob o método da Análise do Discurso de Linha Francesa e da perspectiva Ecocrítica - que estuda as imbricações entre a Literatura e a Ecologia -, as relações homem-ambiente e as representações do sertanejo e do sertão que o escritor José de Alencar delineia na obra $O$ Sertanejo, dialogando com o sentimento humano que é despertado na interlocução com o lugar, com o ambiente e com o território, tendo em vista os conceitos de topofobia (aversão ao ambiente físico) e topofilia (familiaridade ou apego), propostos, em 1980, pelo geógrafo chinês YiFu Tuan. Os discursos na narrativa demonstram a predominância do sentimento de apego à Caatinga (topofilia), desmistificando, pois, a visão hegemônica topofóbica. Portanto, a Ecocrítica suscita imersões inter e transdisciplinares, representando, assim, um substrato à compreensão das relações homem-ambiente.
\end{abstract}

Palavras-chave: Geografia Humanista, Literatura, relações homem-ambiente.

\begin{abstract}
This research proposes to investigate, under the method of the Discourse Analysis of French Line and of the Ecocritical perspective - which it studies the imbrications between Literature and Ecology -, the human-environment relations and the representations of the sertanejo and of the sertão that the writer José de Alencar outlines in the work The Sertanejo, dialoguing with the human feeling that is awakened in the dialogue with the place, the environment and the territory, considering the concepts of topophobia (aversion to the physical environment) and topophilia (familiarity or attachment), proposed in 1980 by Chinese geographer Yi-Fu Tuan. The discourses in the narrative demonstrate the predominance of the feeling of attachment to the Caatinga (topophilia), thus demystifying the topophobic hegemonic view. Therefore, Ecocritique raises inter and transdisciplinary immersions, thus representing a substrate for the understanding of human-environment relations.
\end{abstract}

Keywords: Humanistic Geography, Literature, human-environment relations.

\section{INTRODUÇÃO}

Inicialmente, vale pontuar que, de acordo com Alpina Begossi (1993, p. 123), a origem do termo "Ecologia" vem da Biologia e tem se diversificado, ampliando para Ecologia Humana, 
Ecologia Social, Ecocrítica, desencadeando, assim, inúmeras ramificações, em virtude da profícua relação com Filosofia, Antropologia, Sociologia, Literatura, assumindo, pois, um caráter efetivamente interdisciplinar e transdisciplinar.

Nesse panorama de múltiplas análises em torno da relação homem-ambiente, no final da década de 1970, a partir dos trabalhos do norte-americano William Rueckert, que se notabilizou no cenário da Literatura americana, começou-se a discutir a necessidade de se evidenciar a arte como forte difusora de conhecimentos, mais precisamente a Literatura, através de obras que representam a realidade humana na imbricação com o ambiente, a sociedade e a cultura conforme advogou Rueckert, quando publicou, em 1978, o artigo intitulado "Literature and ecology: An Experiment Ecocriticism".

Outrossim, em 1978, pela primeira vez, destacou-se o termo Ecocrítica na conjuntura acadêmica. Desse modo, quando se alude à Ecocrítica refere-se à relação da arte com a natureza, com o ambiente, com a ecologia. Nesse sentido, vale frisar que o precursor desse termo, conforme Branch (1994, p. 4), foi o norte-americano William Rueckert que defendeu ser a Ecocrítica a aplicação de conceitos ecológicos ao estudo da arte literária. Entretanto, esse estudo só passou a ser efetivamente considerado a partir de 1989, quando Cheryll Glotfelty, participando do Encontro da Associação de Literatura do Oeste dos Estados Unidos, fomentou o seu uso no campo crítico.

Isso posto, Glotfelty (1996, p. 6) sinaliza que a Ecocrítica trabalha sob uma abordagem dos estudos literários centrados na Terra, daí surge uma ferramenta que auxilia os pesquisadores a analisarem as relações homem-ambiente, mediadas por obras literárias que permeiam saberes e percepções do lugar, do ambiente, do território e dos grupos sociais que lá habitam.

Outro intelectual que merece destaque é o norte-americano Greg Garrard (2006, p. 5), quando pondera que a Ecocrítica sugere estudos interdisciplinares. Desse modo, para esta pesquisa, a Ecocrítica dá suporte a uma análise menos reducionista, uma vez que congrega diversos conhecimentos que se intercruzam, favorecendo, assim, a abrangência de olhares em torno das relações homem-ambiente e das representações do sertanejo e do sertão na obra do escritor cearense, José de Alencar, na qual este artigo se debruça.

Dessarte, norteada pelas imbricações várias estabelecidas com diversas ciências, a Ecocrítica relaciona-se, então, com Literatura, História, Filosofia, Sociologia, Antropologia, Geografia, mencionando, somente, algumas das áreas no vasto campo de inter-relações dos saberes em que está inserida, sendo, pois, uma rica perspectiva no universo de possibilidades acadêmico-científicas.

Buscando uma interlocução entre Literatura e Geografia, desponta-se, no cenário técnicocientífico, uma vertente intitulada Geografia Humanista que tem como escopo investigar comportamentos e relações entre o humano e o lugar habitado. Consoante Yi-Fu Tuan (1982, p. 31), a quem se destina a origem do termo, a Geografia Humanista busca delinear uma compreensão do 
mundo humano mediante o estudo das relações das pessoas com a natureza, além dos seus sentimentos e ideias acerca do ambiente e do lugar.

Seguindo a linha de raciocínio de Tuan (1982, p. 32), é a subjetividade (emoções, sentimentos), conectada ao meio, que aponta a possibilidade de definição de dois termos: topofilia que remete à familiaridade e ao apego ao lugar - já que topo denota lugar e filia relaciona-se à filiação e topofobia, que traz uma significação inversa, haja vista que fobia alude à aversão, tornando-se o lugar do medo, da repugnância. Dessa forma, essa subjetividade pode ser marcada tanto pela afeição quanto pelo desprezo, destacando, assim, essas emoções contraditórias que permeiam o universo humano.

Portanto, as contribuições de Tuan (1980, p. 15) revelam que há tanto o apego quanto o horror no que tange ao trinômio seres humanos-lugar-natureza. Nesse ínterim, as percepções topofílicas e topofóbicas podem, certamente, ser encontradas na arte literária, visto que, de acordo com Antonio Candido (2009, p. 13), um importante crítico da Literatura Brasileira, o objeto literário não existe sem a personagem de ficção e esta tem a vida traçada conforme certas condições de espaço que influenciam, diretamente, a sua trajetória na trama.

Ademais, conforme Alfredo Bosi (2006, p. 13), os personagens de ficção, na maioria dos enredos literários, apresentam-se como verossímeis, ou seja, representam figuras reais que existiram em determinado tempo e espaço, perpassando, assim, saberes históricos, geográficos, sociológicos e culturais que ainda permanecem na sociedade atual ou que sofreram transformações diacrônicas e se oferecem como elementos de identificação para o leitor.

Na obra $O$ Sertanejo, do escritor cearense José Alencar, apresenta-se o protagonista Arnaldo, um sertanejo honrado e corajoso conforme atesta o seguinte trecho: "Destemido vaqueiro cearense" (ALENCAR, 2002, p. 9). Segundo Proença (1966, p. 17), o homem sertanejo é o valente, o honrado, o melhor. Há um mito antigo do sertão e essa visão é, claramente, estampada nesta obra alencarina que, apesar de se incluir na prosa regionalista do Romantismo brasileiro, ainda mantém uma significativa ligação com a primeira geração da poesia romântica, na qual aborda o índio como um guerreiro de qualidades superiores (honra, coragem) e, de modo análogo, essas mesmas características são referenciadas ao sertanejo no livro em apreço.

Entretanto, essa representação mítica do sertanejo como um homem, inteiramente, bom, honrado e corajoso, próprio da teoria do bom selvagem, do filósofo iluminista Jean-Jacques Rousseau (1986, p. 73), não considera os estudos do pai da Psicanálise. Conforme Freud (1915a, p. 31; 1915b, p. 21), há duas pulsões que permeiam a essência humana: a de vida - Eros e a de morte - Tanatos. Posto isso, esses universos duplos não são antagônicos, mas se complementam, ora aflorando mais um; ora, com a predominância do outro. E essa dualidade faculta ao ser humano lidar com as diversas facetas da vida. 
Outra contribuição para essa análise vem do pai do Evolucionismo. Nesse sentido, segundo a análise da obra “A Descendência do Homem”, de Darwin (1981, p. 66), mencionam-se duas vezes a sobrevivência do melhor e noventa e cinco vezes a palavra amor. Desse modo, apesar de grande divulgação quanto à competição como preponderante característica humana, levantada por Darwin, o que prevalece na obra em epígrafe é o comportamento como colaboração. Sendo assim, o modelo darwiniano é tanto cooperativo (pulsão de vida) quanto competitivo (pulsão de morte) assim como defendeu Freud (1915a, p. 31; 1915b, p. 21).

Diante dessas considerações, a representação do sertanejo na obra de igual nome, de José Alencar, é utópica quanto a essas características altruístas do homem, visto que as contradições humanas ficam veladas, sendo perpassadas, apenas, o ponto de vista do narrador que deve, pois, ser confrontado com outras concepções, com o fito de que sejam evidenciadas outras percepções, mais próximas da realidade. Para melhor informar o leitor sobre $O$ Sertanejo, vale destacar que a obra é densa, composta por quarenta e um capítulos, distribuídos em duas partes que expõem uma considerável referência às relações homem-ambiente na representação do sertanejo e do sertão.

Para o crítico literário Antonio Candido (1981, p. 23), o romance O Sertanejo, de José de Alencar, representou a realidade a partir do ponto de vista do narrador e da posição afetiva que promoveu o nacionalismo literário, descrevendo lugares num verdadeiro trabalho de mapeamento do país, caracterizado por uma ânsia topográfica de descobrir o território brasileiro, como por exemplo, o sertão que se tornou uma região literária.

Nesse panorama, ressalta-se que, conforme Alfredo Bosi (2006, p. 20), José Martiniano de Alencar Júnior foi um escritor bem ao gosto do público do século XIX, tornando-se, pois, um notório romancista, sendo escolhido por Machado de Assis para patrono da Cadeira n. ${ }^{\circ}$ 23, da Academia Brasileira de Letras. Em sua vida de férteis produções, foi escritor, jornalista, advogado e político. Apesar de uma existência intensa, esta lhe foi breve, falecendo aos 48 anos (1829-1877), no Rio de Janeiro, vítima de tuberculose conforme apregoa Araripe Júnior (1958, p. 36).

O Sertanejo, último romance regionalista do autor, congrega uma série de críticas em torno da verossimilhança da paisagem e de tudo que é narrado na obra, uma vez que Alencar, de acordo com Araripe Júnior (1958, p. 37), renomado crítico literário, produziu essa obra com base em informações colhidas na época e conforme a sua fértil imaginação.

Assim sendo, Alencar, embora tenha se destacado na conjuntura da advocacia, não se defendeu das críticas da época, corroborando, de certo modo, o que se publicava acerca de suas obras. Dessa maneira, Alencar, apesar de deixar livre o seu espírito criativo no livro O Sertanejo, ainda assim, expressou-se, em alguns fragmentos, com verossimilhança, dando vazão a possíveis reflexões sobre o sertanejo e o sertão e, portanto, estabelecendo relações entre esse homem singular e o ambiente circundante. 
Mediante o exposto, este trabalho tem o objetivo de analisar as representações do sertanejo e do sertão que o autor delineia, dialogando, também, com o sentimento que é despertado na interlocução com o lugar, com o ambiente e com o território, tendo em vista os conceitos de topofobia e topofilia. Ressalta-se, também, que esta investigação parte da hipótese de que o discurso topofílico sobressai-se em comparação ao topofóbico.

\section{MATERIAL E MÉTODOS}

A partir desses elementos contextuais, vale frisar que esta pesquisa assenta-se na primeira parte do livro O Sertanejo (1875/2002), de José de Alencar, que reúne vinte capítulos com idealizações e verossimilhanças. No entanto, este estudo centrou-se nestas últimas. Com vistas a realizar esta investigação, adotou-se o método da Análise do Discurso de Linha Francesa que, segundo Michel Pêcheux (1975, p. 8), não há discurso sem sujeito e não há sujeito sem ideologia. Isso posto, o indivíduo é questionado em sujeito pela ideologia e é, assim, que a língua faz sentido.

Dessarte, Eni Orlandi (2012, p. 5) corrobora a Análise do Discurso de Linha Francesa na qual considera as condições de produção em que a obra foi escrita, o contexto histórico-social do país e a história de vida do autor, destacando, pois, essas três características como muito relevantes para a análise deste estudo, visto que é através dessas ferramentas que será realizada a análise do discurso na obra em questão. Ademais, na concepção de Orlandi (2012, p. 6), há de se levar em consideração os fatores histórico-sociais que envolveram a produção do discurso e também os sentidos implícitos e explícitos do texto.

Vale apontar, ainda, que, na análise do discurso consoante Orlandi (2012, p. 7), procura-se compreender a língua fazendo sentido, enquanto trabalho simbólico na relação do homem/personagem com a sua história e com as construções sociais, norteada pela capacidade de significar e significar-se, validando, assim, tais sentidos no discurso do autor através das considerações de suas condições de produção as quais compreendem, principalmente, o sujeito e a situação (contexto imediato e contexto amplo).

Nesse sentido, salienta-se que, para compreender as condições de produção no que tange ao sujeito que enuncia - José de Alencar - e a situação, foi realizada pesquisa bibliográfica relacionada ao autor e ao período histórico em que se insere a obra $O$ Sertanejo, além de ter sido considerada a ideologia intrínseca ao discurso produzido pelo sujeito que fala no texto consoante os estudos de Pêcheux (1975, p. 8).

Sendo assim, para construir o marco teórico deste artigo, foram acessadas 36 publicações, dentre elas: artigos científicos, localizados em periódicos online e em anais de eventos disponíveis eletronicamente e que se referem às primeiras décadas dos anos 2000, além de e-books e livros de 
críticos literários brasileiros, cuja totalidade do referencial teórico data de 1900 (aporte clássico) até consultas que foram realizadas em sites da internet no primeiro semestre de 2021 .

\section{RESULTADOS E DISCUSSÃO}

\subsection{As relações homem-ambiente e as representações do sertanejo e do sertão na obra alencarina $O$ Sertanejo}

A Literatura, concebida como a arte da palavra conforme Antonio Candido (2009, p. 11), procurou historicamente, através de seus personagens, representar a realidade ou, até mesmo, serviu de instrumento de idealização, com o propósito de evadir da realidade, ficando, pois, encoberta, tendo em vista o alcance de objetivos do autor, com o fito de corresponder aos anseios da época. Desse modo, Araripe Júnior (1958, p. 38) é categórico ao afirmar que José de Alencar não viu o sertão que descrevera, não tendo, pois, saído do entorno da capital cearense, Fortaleza. Sendo assim, para Araripe Júnior (1958, p. 38), Alencar ignorava completamente a vida do sertanejo. Todavia, Alencar procurou retratá-la com as vozes dos seus informantes e suas percepções imagéticas, razões pelas quais não se pode precisar a veracidade de tais descrições.

Nessa perspectiva, ainda que o livro $O$ Sertanejo tenha sido escrito sob a égide do Romantismo, período histórico-literário marcado pela liberdade de expressão e pela idealização dos personagens mediante o recurso da fuga da realidade, em excertos da primeira parte desta obra, verificam-se descrições e narrações que suscitam representações reais para aquela época - século XIX, fazendo-se pulsante, em certa medida, como um pensamento vigente ainda na atualidade.

No primeiro capítulo intitulado “O Comboio”, José de Alencar, considerando que a obra em exame é autobiográfica, evoca uma subjetividade que é fortemente marcada pela topofilia (apego ao lugar). Essa percepção pode ser reverberada a partir dos seguintes trechos: "Esta imensa campina é o sertão de minha terra natal"; quando te tornarei a ver, sertão da minha terra, que atravessei há tantos anos na aurora serena e feliz da minha infância?"; "Quando tornarei a respirar tuas auras de perfumes agrestes?" (ALENCAR, 2002, p. 9).

Embora Alencar tenha sido um cidadão metropolitano que residiu, preponderantemente, em cidades brasileiras de grande porte (Rio de Janeiro-RJ, São Paulo-SP, Olinda-PE), soube captar a sensibilidade dos sertanejos que são obrigados a migrar de sua terra natal, mas mantêm, mesmo distantes, o amor pelo solo onde nasceram, permanecendo, pois, as indeléveis reminiscências da infância.

Essa migração do sertanejo pode acontecer de duas formas: pela certeza de oportunidades em centros culturais e econômicos, motivadas por condições sociais abastadas como foi o caso de Alencar ou pela esperança de dias melhores, razão primeva do êxodo rural entre os nordestinos 
campesinos desprivilegiados economicamente, em face de políticas excludentes que expulsaram o sertanejo de sua terra natal, deixando, em seu íntimo, a melancolia e a saudade do seu lugar de origem.

Vale acrescentar que José de Alencar nasceu no sítio Alagadiço Novo, Mecejana, Ceará e só se mudou para o Rio de Janeiro com 10 anos de idade. Logo, essas lembranças pueris acerca da terra natal podem ser, categoricamente, autobiográficas, embora Araripe Júnior (1958, p. 38), um ferino crítico da obra alencarina, afirme que o autor de $O$ Sertanejo não tinha propriedade para descrever, com realismo, o sertão onde nascera nem, tão pouco, teria sensibilidade para captar a subjetividade de outros tantos sertanejos que migraram de suas raízes territoriais.

Nessa tônica, ainda, é oportuno esclarecer que, segundo Alfredo Bosi (2006, p. 22), a crítica implacável que Araripe Júnior faz à obra de Alencar pode ser explicada, muito mais, em face de problemas políticos do que meramente literários, uma vez que o autor de $O$ Sertanejo foi alvo de uma campanha sistemática contra as suas obras, liderada por jornalistas e críticos da época, em virtude, talvez, de sua posição contrária à administração do imperador.

Essa conjectura pode ser ratificada, considerando o fato de que Alencar passou a publicar sob o pseudônimo de Sênio e a maioria dos jornalistas e críticos que o aviltavam lhe direcionaram elogios, bem como a sua escrita. Desse modo, fica patente a perseguição política de que foi vítima, o que provocou, na época, uma sucessão de críticas infundadas para macular o engenho artístico-literário que lhe era peculiar.

Ademais, reitera-se que, levando em conta a citação do primeiro capítulo: "Esta imensa campina é o sertão de minha terra natal"; "Quando te tornarei a ver, sertão da minha terra" (ALENCAR, 2002, p. 9), é possível, claramente, identificar uma descrição autobiográfica, pois o autor, nascendo no sítio Alagadiço Novo, Mecejana-CE e lá permanecendo até os 10 anos de idade, narra as suas emoções e reminiscências da infância que ficaram gravadas em sua memória, despertando, assim, o desejo de retornar a sua terra natal e reviver essas agradáveis lembranças.

Outrossim, a partir desses fragmentos, percebe-se um profundo sentimento de pertencimento histórico ao território e ao lugar onde autor e personagem viveram uma infância "feliz e serena" (ALENCAR, 2002, p. 9) em meio à exuberância e à biodiversidade da paisagem sertaneja, contrariando, assim, descrições hegemônicas, como por exemplo, chão rachado e terra inóspita, parafraseando, apenas, algumas expressões utilizadas por escritores, como Euclides da Cunha, na obra Os Sertões.

Retomando a ideia de felicidade, trazida pelo sentimento de pertencimento histórico, salienta-se que esta corrobora o pensamento de Freud (1900, p. 45) quando o pai da Psicanálise afirma que a felicidade é a realização de um desejo pré-histórico, ou seja, antigo, da infância. Por isso, segundo a psicanálise freudiana, dinheiro não traz felicidade, pois uma criança não deseja ter dinheiro. Desse modo, a alusão que o adulto faz a sua infância, seja o local físico ou as pessoas e 
acontecimentos, representa uma demanda do ser humano sempre acompanhada de muita satisfação, quando realizada.

Nesse contexto, consoante Freud (1900, p. 45), a felicidade, sendo a materialização de um anseio da infância, é atingida quando o adulto realiza tal desejo, com destaque ao fato de que essa realização pode ser alcançada no mundo concreto, como por exemplo, mediante uma visita ao local ou às pessoas com as quais manteve, no passado, uma relação de afeto ou ainda, de forma indireta, através de lembranças de fantasias expressadas através da arte.

Em se tratando da imagem negativa e hegemônica do sertão, reitera-se que essa caracterização, segundo Martins (2006, p. 11), foi difundida historicamente no Brasil pelas elites políticas, econômicas e culturais - e, assim, a caatinga ficou conhecida como uma região inóspita, de vegetação seca. Em contraposição, outras correntes de intelectuais vêm se afirmando, como por exemplo, as perspectivas da decolonialidade (MIGNOLO, 2010, p. 12) e da Ecologia de Saberes (SANTOS, 2007, p. 73) que valorizam as potencialidades de grupos e regiões que foram excluídos historicamente, como os sertanejos e o sertão, criando, assim, a subversão de um não-dito nativista e sertanista.

Retomando o livro $O$ Sertanejo, vale realçar que, embora o narrador apresente, na maioria dos trechos da obra, um profundo amor à sua terra natal, não deixa de relatar, também, a diversidade e a ambivalência da paisagem: "ora seca e triste, ora alegre e poética" (ALENCAR, 2002, p. 14) conforme coadunam os excertos seguintes: "A chapada tinha o aspecto desolado e profundamente triste que tomam aquelas regiões no tempo da seca. Dir-se-ia que por aí passou o fogo e consumiu toda a verdura, que é o sorriso dos campos nos tempos de chuva" (ALENCAR, 2002, p. 14).

A partir desses trechos, verifica-se que o narrador de $O$ Sertanejo descreve, "poeticamente", a fitofisionomia da Caatinga que, conforme Silva et al., (2004, p. 11), apresenta clima semiárido, vegetação com poucas folhas e adaptadas para os períodos de seca. Nessa época, quase todas as plantas perdem as folhas para diminuir a transpiração e evitar a perda de água armazenada. No inverno, devido à ocorrência de chuva, as folhas verdes e as flores voltam a brotar. Entretanto, mesmo em meio a essa irregularidade, na Caatinga, há uma considerável biodiversidade, seja de flora, seja de fauna.

Ainda ressaltando essa dualidade da paisagem, característica típica da fitofisionomia da Caatinga, apresenta-se o fragmento que se segue: "Estes ares, em outra época povoados de turbilhões de pássaros loquazes, cuja brilhante plumagem rutilava aos raios do sol, agora ermos e mudos como a terra, são apenas cortados pelo voo pesado dos urubus que farejam a carniça" (ALENCAR, 2002, p. 15). Aqui se mostram dois momentos de percepção do sertão: um, repleto de vida, marcado pelo canto dos pássaros: topofilia - atração pelo lugar; o outro, com a presença da morte, num ambiente inóspito, permeado de solidão, silêncio e decomposição: topofobia - repulsa ao lugar. 
Dessa forma, constata-se que Alencar evidencia, nos fragmentos acima, tal oscilação do tempo e da paisagem que são típicos dessa vegetação. Vale ressaltar que, oficialmente, a Caatinga é classificada como Savana Estépica (VELOSO et al., 1991, p. 15), embora mais recentemente, em nível internacional, esse Bioma venha sendo considerado como parte das Florestas Tropicais Sazonalmente Secas - STDF (OLIVEIRA FILHO et al., 2006, p. 168).

É válido frisar que, historicamente, as narrativas sobre o sertão, provindas do Sul e Sudeste do país, salientam, apenas, um dos aspectos da Caatinga: a fisionomia seca, sem vida e, portanto, sem potencial de desenvolvimento. Por isso, perpassou-se a imagem hegemônica de exclusiva pobreza e miséria. Entretanto, a Literatura, seja artística (O Sertanejo) ou contra-hegemônica, descortina o outro aspecto da Caatinga: viva, rica e abundante que precisa ganhar visibilidade no cenário nacional.

Para Martins (2006, p. 12), é preciso contextualizar e descolonizar, para que o sertão e os saberes do sertanejo sejam reconhecidos e valorizados, uma vez que se faz necessário desconstruir o pedantismo europeu que foi herdado pela cultura brasileira, prevalecendo como único conhecimento válido e cientificamente comprovado. Ressalta-se, também, que, conforme Martins (2006, p. 12), isso é perpassado pelo conhecimento hegemônico, localizado no Sudeste, onde se instala, majoritariamente, a indústria editorial e midiática que exerce, portanto, forte influência na formação de opiniões e "verdades" na federação.

Considerando essa assertiva, desconstruir uma imagem errônea do sertão e do sertanejo é um árduo empreendimento que deve ser planejado e executado pelos intelectuais que visam à descolonização e, por conseguinte, à emancipação dos territórios, dos grupos sociais e dos sujeitos que foram excluídos social e historicamente.

Ademais, infere-se que as alterações do ambiente moldam a subjetividade do sertanejo. Desse modo, as modificações da paisagem (árida, seca para verde e exuberante) determinam os sentimentos do sertanejo, ou seja, o seu universo de emoções, marcado por sensações positivas (bemestar, alegria) ou negativas (tristeza, solidão, morbidez). Essa constatação pode ser reverberada pelo trecho:

Quem pela primeira vez percorre o sertão nessa quadra, depois de longa seca, sente confranger-se-lhe a alma em face dessa inanição da vida, desse imenso holocausto da terra. É mais fúnebre do que um cemitério, não é mais do que o vasto jazigo de uma natureza extinta e o sepulcro da própria criação (ALENCAR, 2002, p. 16).

Analogamente, essas sensações (positivas ou negativas), em face das transformações da paisagem do semiárido, podem ser associadas à bivalência das "pulsões de vida e de morte", discutidas por Freud (1915a, p. 31, 1915b, p. 21) e a dualidade "cooperação e competição", exposta por Darwin (1981, p. 66). Nessa perspectiva, diante da escassez de recursos, em virtude das adversidades sazonais provenientes de longos períodos de estiagem, tanto o ambiente como o sertanejo absorvem as emoções negativas, desencadeando, assim, a pulsão de morte e o espírito 
competitivo, a fim de que sobrevivam em meio a uma caatinga seca e a uma vida plasmada de dores, perdas e privações.

Revisitando a dupla fitofisionomia da caatinga: ora seca e morta, ora verde e exuberante, verifica-se que a descrição negativa ("pulsão de morte e competição") não é unânime. Entretanto, é a mais difundida pela mídia hegemônica e, por ser a mais impactante e a que melhor reproduz a noção etnocêntrica das regiões Sul e Sudeste, é a que prevalece no imaginário dos brasileiros de ínfimo senso crítico e de reduzida propriedade intelectual sobre essa ambivalência da caatinga.

Em contraponto, o protagonista da obra $O$ Sertanejo e outros personagens da trama, mesmo estando imersos num ambiente árido em grande parte do ano, mostram-se apegados à terra onde nasceram, revelando um profundo sentimento de pertencimento ao lugar - topofilia, despertando, assim, uma relação subjetiva com o espaço onde viveram e com as paisagens com as quais conviveram, construindo, assim, laços afetivos com o território.

Esse cenário pode ser constatado mediante os fragmentos que se seguem: "E ela experimentava um indizível prazer, como se a terra de seu berço lhe abrisse os braços carinhosa e a estivesse apertando ao seio e cobrindo-lhe as faces de beijos" (ALENCAR, 2002, p. 19). Conforme Hutta (2020, p. 65), os territórios são, inerentemente, afetivos e essa dimensão simbólica tem sido tratada, comumente, através de noções como "topofilia", o que enfatiza o elo entre as pessoas e um lugar, assim como ocorre na obra em questão.

Haesbaert (2004, p. 15) corrobora essa tendência dos territórios afetivos quando afirma que, frequentemente, o termo territorialidade tem sido utilizado para enfatizar a apropriação subjetiva do território e a construção de uma identidade territorial através de registros simbólicos, em oposição a outra vertente de análise que concebe o território relacionado à dominação político-econômica dos atores e ao controle de espaços. Dessarte, a obra $O$ Sertanejo vem coadunar essa primeira perspectiva, exposta pelo referido autor.

Retornando à apreciação da obra $O$ Sertanejo, pontua-se que, no segundo capítulo intitulado "O Desmaio", é narrado um incêndio no sertão do Ceará que expõe uma visão consciente do narrador que, assim, descreve o ocorrido: “O incêndio, causado por alguma queimada imprudente, propagavase com fulminante rapidez pelas árvores mirradas que não passavam então de uma extensa mata de lenha" (ALENCAR, 2002, p. 25).

A partir desse fragmento, verifica-se que o narrador considera a prática das queimadas um ato insensato, alertando, pois, o leitor para um problema ambiental que acontecia na época e, hoje, ainda em maior proporção, em virtude do avanço do capitalismo contemporâneo que se sobrepõe à ciência da sustentabilidade ou, na outra ponta, em virtude do desconhecimento do sertanejo quanto a formas sustentáveis de manejo da terra, uma vez que o conhecimento científico, não raro, fica restrito 
às elites culturais e econômicas, excluindo, pois, grupos humanos invisibilizados do acesso a esse saber.

Conforme Santos (2007, p. 75), o pensamento moderno ocidental é abissal, uma vez que foi construído mediante as linhas cartográficas que demarcavam o território em Velho e Novo Mundo. Desse modo, na visão eurocêntrica, existe "este lado da linha" que centraliza o conhecimento científico e "o outro lado da linha" que fica excluído do acesso ao conhecimento social e historicamente construído. Daí, a partilha de saberes, igualmente válidos, deve integrar as diversas culturas, socializando, pois, os conhecimentos construídos, a fim de que todos os grupos humanos sejam beneficiados.

Para Guattari (1990, p. 32), existem inúmeros fenômenos de impactos ecológicos que, se não forem remediados, no limite, ameaçarão a vida em sua superfície. Paralelamente a tais perturbações, os modos de vida humanos individuais e coletivos evoluem no sentido de uma progressiva deterioração. Daí, uma grande preocupação que permeia o homem contemporâneo, pois ele, inserido nos diversos ecossistemas, tem ultrapassado os limites da sustentabilidade e está destruindo a casa comum dos seres do planeta - o ambiente natural e todas as relações que a ele se imbricam.

Nesse panorama, é preciso pensar a ideia de catástrofe na Terra mediante a exaustão dos ecossistemas pela devastadora ação antrópica a partir da extinção dos recursos naturais e minerais. Daí, faz-se mister uma nova racionalidade que alie a sustentabilidade planetária a um desenvolvimento ético (SANTOS, 2003, p. 58) capaz de garantir uma morada mais humanizada, atendendo, pois, as necessidades presentes e futuras de maneira consciente e geradora de vida na relação do homem com os diversos ambientes em que está incluído. Seria, pois, a Teoria da Modernização Ecológica (TME), que, de acordo com Marques (2014, p. 67), prevê o desenvolvimento econômico com sustentabilidade.

Outro aspecto marcante neste segundo capítulo da obra em exame é a religiosidade cristã do sertanejo, percebida na representação de sua fé em meio às adversidades e à humildade, estampada num espírito de gratidão. Isso pode ser confirmado na passagem: “Ajoelhou então o sertanejo à beira do canapé; tirando do peito uma cruz que trazia ao pescoço. Com as mãos postas, murmurou uma ave-maria, que ofereceu à Virgem como ação de graças por haver permitido que chegasse a tempo de salvar" (ALENCAR, 2002, p. 30).

Embora a obra $O$ Sertanejo, de José Alencar, tenha sido escrita no final do século XIX, essa religiosidade aguçada ainda se configura como atual, imprimindo-se como uma característica cultural, típica do sertanejo, passível de estudos mais aprofundados para descortinar o apreço desse grupo social ao catolicismo, coadunado pelos símbolos: “ajoelhou”, “cruz”, “mãos postas”, "ave-maria”, "Virgem". 
Segundo Santos (2013, p. 118), todo ano é a mesma coisa e esperar parece ser a sina do sertanejo que, ansiosamente, aguarda os sinais de chuva, mas essa espera é marcada por profunda religiosidade, sempre acreditando nas bênçãos do Nosso Senhor. Para Silva Júnior (2009, p. 60), o sertanejo, geralmente, está envolto numa atmosfera de resignação aos ditames de Deus.

No terceiro capítulo intitulado "A Chegada”, a fé do sertanejo é novamente destacada como pode ser observado no trecho que se segue: "Caiu de joelhos, dando graças a Deus" (ALENCAR, 2002, p. 39), evidenciando, assim, um forte elemento cultural do sertão nordestino. Desse modo, constata-se que a fé pode ser traduzida como um elemento de esperança para o sertanejo que fica em evidência na relação com a experiência do cotidiano, sobressaindo, assim, a pulsão de vida conforme Freud (1939, p. 31). Por conseguinte, a fé (pulsão de vida) representa um contributo indispensável à superação das adversidades diante das alternâncias (pulsão de vida e pulsão de morte), intrínsecas ao habitat sertanejo.

Para Silva (1982, p. 12), a interferência do divino no sertão estava muito além do espaço da igreja ou de seus sacramentos, estava relacionada, também, à vida mundana e cotidiana. Desse modo, a relação do sertanejo com Deus é íntima e direta, fazendo parte da sua labuta diária, não estando, portanto, diretamente, ligada a templos ou arquiteturas, mas presente na natureza e em todos os espaços (uma força onipresente).

No quarto capítulo intitulado "A Herdade", o narrador expõe a íntima relação do sertanejo com a flora, cuja história e afetividade são perpassadas de geração a geração, uma vez que a "oiticica" foi preservada pelos antepassados sertanejos, tendo, pois, uma carga semântica significativa para os seus descendentes e esse apego à planta (topofilia), muitas vezes, é tão intenso que o sertanejo a homenageia, como por exemplo, dando o nome dela a sua terra, a sua fazenda conforme ocorreu na obra em questão.

Essa relação afetiva entre a vegetação e o homem pode ser reverberada nos seguintes trechos: " $\mathrm{Na}$ frente, elevava-se no terreiro a frondosa oiticica, donde viera o nome à fazenda. Era um gigante da antiga mata virgem, que outrora cobria aquele sítio"; "Na ocasião da derrubada, sua majestosa beleza moveu o fazendeiro a respeitá-la” (ALENCAR, 2002, p. 46). Nesse contexto, prevalece o aspecto simbólico e subjetivo do sertanejo que mantém laços de afetividade com o lugar, com a paisagem e com o seu território (topofilia).

No quinto capítulo intitulado "Jó", podem ser constatados outros fragmentos que denotam a afetividade do homem com a vegetação, a saber: "E buscou a sua malhada favorita. Era esta um jacarandá colossal. Ali costumava o sertanejo passar a noite ao relento" (ALENCAR, 2002, p. 66). Essa relação afetiva e aprazível do sertanejo com a flora local vem corroborar, mais uma vez, a tendência, predominantemente, topofílica, encontrada na obra $O$ Sertanejo. 
Vale destacar que, nos dois capítulos seguintes, não houve, na obra em apreço, alusões à temática deste artigo. Relativamente ao oitavo capítulo intitulado "Dois Amigos”, retornam os trechos topofóbicos, quando ocorre a referência ao sertão: "Seca muita, já se sabe! Olhe, digam vocês o que quiserem, isto não é terra de cristão" (ALENCAR, 2002, p. 89), revelando, assim, uma repulsa ao lugar, comparando-o a um espaço desagradável, inóspito. Todavia, esses trechos têm menor recorrência na obra em questão, reverberando, pois, sua tendência topofílica.

Nesse viés, em seguida, aparecem sucessivos fragmentos topofílicos, a saber: "De cristão é que ela é, pois ao cristão ensinou o divino mestre a paciência e o trabalho. Para quem não serve a minha terra é para aqueles que não aprendem com ela a ser fortes e corajosos" (ALENCAR, 2002, p. 89), reforçando, assim, o apego ao lugar, demonstrado pelo sertanejo, apesar das adversidades, além de reiterar a representação do sertanejo como uma pessoa destemida e de espírito combativo.

No décimo capítulo intitulado "O Rosário", o sertanejo descreve a sua subjetividade quando começam a cair as primeiras chuvas no sertão nordestino: “A primeira gota d'água que cai das nuvens é o beijo de amor trocado entre o céu e a terra" (ALENCAR, 2002, p. 116). Desse modo, verifica-se que as mudanças do tempo e do ambiente alteram as emoções e as percepções do sertanejo frente à vida e ao próprio sertão como expõem os excertos: “Aquela árvore que ainda ontem parecia um tronco morto já tem um aspecto vivaz” (ALENCAR, 2002, p. 117); “O espaço, até ali mudo e ermo na limpidez de seu azul diáfano, começava por igual a povoar-se dos pássaros que, durante a seca, emigram para climas amenos" (ALENCAR, 2002, 118).

Por conseguinte, as representações do sertanejo e do sertão que José de Alencar delineia na obra $O$ Sertanejo são, predominantemente, topofílicas, ou seja, apresentam uma substancial carga semântica de afetividade, de apego ao lugar, ao território e às paisagens locais num sentimento de pertencimento que aflora do mundo subjetivo do personagem/autor na relação com o ambiente. Isso posto, entre personagem e autor, há uma identificação projetiva. Em outras palavras, observa-se, explicitamente, uma conjunção ficção-realidade, evidenciando-se, pois, elementos culturais e simbólicos que convergem para ambos.

Consoante Ribeiro (2016, p. 134), o conceito de identificação projetiva foi postulado por Melanie Klein, em 1946, no texto "Notas sobre alguns mecanismos esquizoides", um clássico da literatura psicanalítica. Para a autora, a identificação projetiva pode ser compreendida como uma fantasia inconsciente entre analista e analisando e, de modo análogo, entre autor e personagem, podendo ter um caráter mais agressivo, expulsivo e, portanto, defensivo ou um caráter mais comunicativo, sendo que os mecanismos de cisão e projeção, em intensidades diversas, estão sempre implicados. Sendo assim, autor e personagem estão imbricados numa relação identitária, uma vez que os personagens de um autor são as projeções dos desejos autorais. 


\section{CONSIDERAÇÕES FINAIS}

Vale ponderar que, enquanto subjetividade, o sertão é, prioritariamente, topofílico para José de Alencar e, consequentemente, para a grande parte dos personagens que constituem a sua obra, visto que, no universo ficcional, relativamente à identificação projetiva, os personagens podem refletir os seus respectivos autores. Nesse sentido, a análise da topofilia e da topofobia, no contexto da Ecocrítica, implica as conflitantes conexões entre os seres humanos, a Literatura e o lugar e, embora as relações de apego e repulsa ao ambiente físico sejam paradoxais, uma delas não pode ser velada, historicamente, como se não existisse no que concerne às representações do sertanejo e do sertão.

Nesse aspecto, a topofilia precisa ganhar fôlego no cenário acadêmico, midiático e político, com vistas a desconstruir uma imagem, exclusivamente, topofóbica acerca do sertão e do sertanejo que foi veiculada, majoritariamente, na maioria dos meios de comunicação de massa e consolidada por um grupo prestigiado de cientistas, artistas e políticos, o que mascarou a dupla face da caatinga: ora seca e inóspita; ora verde e de rica biodiversidade.

Entretanto, faz-se necessária uma maior visibilidade da caatinga no que tange às imagens topofílicas. Nessa perspectiva, a obra em apreço ilustra bem tais peculiaridades. Ressalta-se, assim, que construções históricas são dissolvidas, paulatinamente, em contato com novos paradigmas e representações. Contrariamente, no período em que o livro $O$ Sertanejo foi escrito e publicado pela primeira vez (1875), vigorava, no país, o abandono da região Nordeste, caracterizada como um lugar improdutivo. Em decorrência disso, foram criadas visões históricas de horror e repugnância que emergiram das linhas científicas, políticas e, até mesmo, literárias que estavam em voga na época.

Outrossim, com o propósito de romper com a topofobia que imperava no final do século XIX, José de Alencar produziu, em O Sertanejo, imagens topofílicas em preponderância, objetivando entrar em choque com sentidos estereotipados e deturpados quanto ao sertanejo e à vegetação predominante na caatinga. Assim, o autor, acusado de um idealismo extravagante, descortinou belezas e potenciais do sertão, até então, encobertos por grupos hegemônicos.

Ademais, mediante a Geografia Humanista, é possível vislumbrar a relação ser humano lugar com outro viés: o do elo afetivo, que tanto pode existir numa vertente de apego (topofilia) como numa face de aversão (topofobia). Todavia, não são, apenas, as percepções de um ou outro sentimento que se fazem presentes no discurso alencarino. Nele, há, também, manifestações da cultura e de valores do sertão e do sertanejo.

Por fim, vale destacar que a Ecocrítica, interlocutora das relações entre Literatura e Ecologia, está carregada, também, de saberes que ultrapassam o campo da representatividade e do concretismo. Nesses termos, Alencar tratou do clima, da paisagem, do território, da fauna e da flora, refutando, 
com a predominância de um discurso topofílico, as narrativas hegemônicas de que o sertão é, tão somente, seco e repugnante e, como tal, um lugar, permanentemente, inóspito.

\section{REFERÊNCIAS}

ALENCAR, J. O Sertanejo. São Paulo: José Olympio, 2002. 570p.

ARARIPE JÚNIOR, T. A. José de Alencar. Rio de Janeiro: Casa de Rui Barbosa, 1958.

BEGOSSI, A. Ecologia Humana: Um Enfoque Das Relações Homem-Ambiente. Interciência, v. 18, n. 1, p. 121-132, 1993.

BOSI, A. História Concisa da Literatura Brasileira. São Paulo: Cultrix, 2006. 707p.

BRANCH, M. P. Defining Ecocritical Theory And Practice. 1994. Disponível em: http://www.asle.org/site/resources/ecocritical-library/intro/defining/. Acesso em: 05 abr. 2021.

CANDIDO, A. Formação da literatura brasileira. Belo Horizonte: Editora Itatiaia, 1981. 800p.

CANDIDO, A. A Personagem de Ficção. São Paulo: Perspectiva, 2009. 128p.

DARWIN, C. Descent of Man. Princeton: Princeton University Press, 1981. 142p.

FREUD, S. A Interpretação dos Sonhos. In: FREUD, S. Obras Completas. Buenos Aires: Amorrortu, 1900. p. 210-240.

FREUD, S. O Inconsciente. In: FREUD, S. Obras Completas. Buenos Aires: Amorrortu, 1915a. p. 28-50.

FREUD, S. Os instintos e suas vicissitudes. In: FREUD, S. Obras Completas. Rio de Janeiro: ESB, 1915b. p. 15-35.

FREUD, S. Moisés e o monoteísmo. Rio de Janeiro: Imago, ESB, 1939. 185p.

GARRARD, Greg. Ecocrítica. Brasília: Editora da Universidade de Brasília: 03-13, 2006,

GLOTFELTY, C. Introduction-literary studies in an age of environmental crisis. In: GLOTFELTY, C.; FROMM, H. (Eds.). The ecocristicism reader: landmarks in literary ecology. London: The Univ. of Georgia Press, 1996. p. 4-11.

GUATTARI, F. As Três Ecologias. Campinas: Papirus, 1990. 56p.

HAESBAERT, R. O Mito da Desterritorialização. Do "Fim dos Territórios" à Multiterritorialidade. Rio de Janeiro: Bertrand Brasil, 11-18, 2004. 396p.

HUTTA, J. S. Territórios afetivos: cartografia do aconchego como uma cartografia de poder. Revista Caderno Prudentino de Geografia, Presidente Prudente, v. 2, n. 42, p. 63-89, 2020. 
MARTINS, J. S. Tecendo a rede: notícias críticas do trabalho de descolonização curricular no SemiÁrido Brasileiro e outras excedências. 2006. 344 f. Tese (Doutorado em Educação) - Faculdade de Educação, Universidade Federal da Bahia, Salvador, 2006.

MARQUES, J. (Org.). Ecologias Humanas. Feira de Santana: Editora UEFS, 2014. 460p.

MIGNOLO, W. D. Aiesthesis Decolonial. Calle, v. 4, n. 4, p. 10-25, 2010.

OLIVEIRA FILHO, A. T.; JARENKOV, J. A.; RODAL, M. J. N. Floristic relationships of seasonally dry forests of eastern South America based on tree species distribution pattern. In: PENNINGTON, R. T.; LEWIS, G. P.; RATTER, J. A. Neotropical savannas and seasonally dry forests. Boca Raton: CRC Press, 2006. p. 159-190.

ORLANDI, E. P. Análise de discurso: princípios e procedimentos. 1. ed. Campinas: Pontes/UNICAMP, 2012. 100.

PÊCHEUX, Michel. Les Vértiés de la Palice, Maspero. Tradução Eno Orlandi. Campinas: Editora da UNICAMP, 1075.

PROENÇA, M. C. José de Alencar na Literatura Brasileira. Rio de Janeiro: Editora José Olympio, 1966.

RIBEIRO, M. F. R. Uma reflexão conceitual entre identificação projetiva e enactment. O analista implicado. Revista Cadernos de psicanálise, Rio de Janeiro, v. 38, p. 132-144, 2016.

ROUSSEAU, J. J. Os devaneios do caminhante solitário. Brasília: Editora Universidade de Brasília - Hucitec, 1986. 187p.

RUECKERT, W. Literature and ecology: un experiment in Ecocriticism. In: GLOTFELTY, C.; FROMM, H. (Eds). The ecocristicism reader: landmarks in literary ecology. London: The Univ. of Georgia Press, 1996. p. 105-123.

SANTOS, B. S. (Org.) Conhecimento prudente para uma vida decente: Um discurso sobre as ciências revisitado. Porto: Afrontamento, 2003. 824p.

SANTOS, Boaventura de Sousa. Para além do pensamento abissal: das linhas globais a uma ecologia de saberes. Revista Novos, v. 72, p. 71-94, 2007.

SANTOS, E. R. Religiosidade sertaneja: amanhecer esperança, adormecer paciência. In: SIMPÓSIO NACIONAL DE HISTÓRIA. 27., 2013, Natal. Anais... Natal, 2013. p. 110-121.

SILVA, J. M. C.; TABARELli, M.; FONSECA, M. T.; LINS, L. V. (Org). Biodiversidade da Caatinga: áreas e ações prioritárias para a conservação. Brasília: MMA/UFPE/Conservation International, 2004.

SILVA, C. C. Roteiro da vida e da morte: um estudo do catolicismo no sertão da Bahia. São Paulo: Ática, 1982.

SILVA JUNIOR, A. S. Homo Religiosus na formação do semiárido cearense. Revista Homem, Espaço e Tempo, v. 3, n. 2. p. 55-70, 2009. 
TUAN, Yi-Fu. Topofilia: um estudo da percepção, atitudes e valores do meio ambiente (trad.) Lívia de Oliveira. São Paulo: DIFEL, 1980.

TUAN, Yi-Fu. Geografia Humanista. In: CRISTOFOLETI, A. (Org.) Perspectivas da Geografia. São Paulo: DIFEL, 1982. p. 29-40.

VELOSO, H. P.; RANGEL-FILHO, A. L. R.; LIMA, J. C. A. Classificação da vegetação brasileira, adaptada a um sistema universal. Rio de Janeiro (RJ): IBGE, 1991. 271p. 